\title{
Journal of Surfactants and Detergents: Cheers to the Next 20 Years!
}

\author{
George A. Smith ${ }^{1}$
}

Published online: 19 September 2017

(C) AOCS 2017

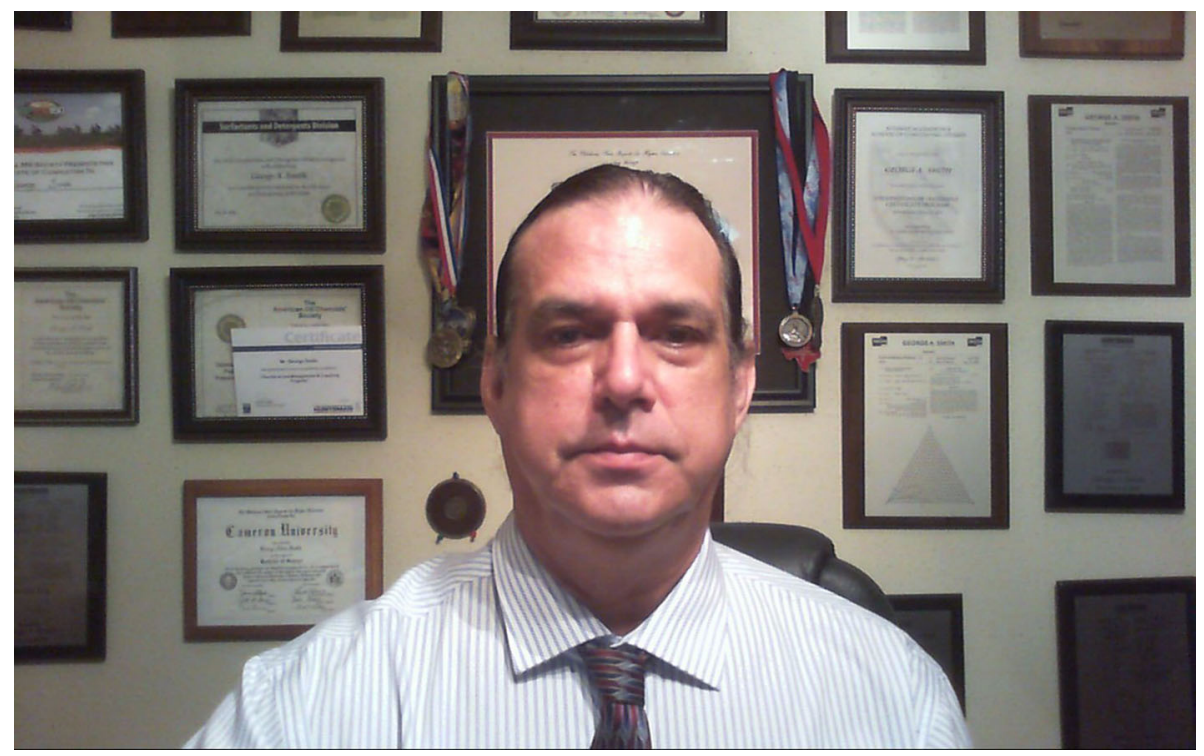

To help celebrate the twentieth anniversary, each issue of $J S D$ in 2017 has featured a guest editorial from past editors. In January, Michael Cox spoke about the early years and the need for a journal to bridge the gap between the fundamental science and industrial application of surfactants. With the help of Arno Cahn and AOCS, JSD was created in 1997 to help fill this unmet need in the surfactants industry. In March, Mark Nace, the second editor-inchief for $J S D$, discussed the critical role of technical editors in helping young authors improve the quality of their manuscripts and the contributions of people like Russ

George A. Smith

george_a_smith@huntsman.com

1 Huntsman Performance Products, The Woodlands, TX, USA
Elms, Catherine Watkins, Lisa Quencer, and Brian Moore in helping to build the editorial team and manage publication of the journal. In July, Jean-Louis Salager, the third editor-in-chief, discussed the transition to Springer and the efforts to improve the originality and scientific quality of the articles published in $J S D$ while maintaining a focus on industrial application of surfactants. Under Jean-Louis's leadership, with the help of the very efficient and always ready administrative assistant Pam Landman, the number of publications more than doubled with JSD going from four to six publications a year in 2012. In September, long time technical editor and contributor to the journal Charles Hammond spoke about JSD's unique position in teaching formulation science to young researchers and industrial application of surfactants. 
In May, as part of the twentieth anniversary celebration, $J S D$ sponsored a special session at the AOCS Annual Meeting to honor Professor Milton Rosen. Co-organized by Dennis Murphy, one of Rosen's former graduate students, the session featured a short video message from Professor Rosen, now age 96, thanking JSD for the honor and congratulating his past graduate students and colleagues on their contributions to surfactant science. The session focused on many of the same topics studied by Professor Rosen, including synergy in surfactant mixtures, surfactant-polymer interactions, and gemini surfactants. JSD plans to publish several papers from the invited speakers over the next few issues.

As the celebration of the JSD twentieth anniversary comes to a close, let me say a few words about the future. Next year, $J S D$ will transition to a new publisher. Since 2006, JSD has been published by Springer Verlag, Germany. With the help of Steffen Pauly at Springer, JSD has increased the number of articles published each year, increased the journal impact factor, and allowed access of the journal to a worldwide audience. Next year we will transition Wiley \& Sons who will help to increase our readership and further improve the scientific quality of the journal. Under the Wiley agreement, AOCS members will have on-line access to all AOCS journals.

Next year, $J S D$ plans to publish a special edition of the 22nd International Symposium on Surfactants in Solution (SIS) to be held in Norman, Oklahoma. Held every 2 years, SIS draws scientists and technologists in the field of colloid and surfactant science from around the world. Brian Grady and Kash Mittal, the symposium organizers will serve as guest editors for the special edition. Additional information is available from the SIS website at https://sis2018.ou.edu/ about/.
Lastly, the editorial board is looking into creating an open access website as a companion to JSD. Over the last 20 years, $J S D$ has published hundreds of papers about the behavior of surfactants in different applications. As is often the case in scientific publications, authors have expressed their results in different units and formats. The proposed website is meant to summarize this information in a searchable database using common units to allow for comparison of different surfactant systems, thus providing an easy-to-use source of information for scientists from industry and academia working in the field of surfactant science. With your help and support, we hope to get this running next year and continue to provide a valuable resource to our readership and contribute to the wonderful world of surfactant science.

gresu ach hith

George A. Smith

Editor-in-Chief

Journal of Surfactants and Detergents

Huntsman Performance Products

The Woodlands, TX

USA

George A. Smith has a Ph.D. in Physical Chemistry from the Institute of Applied Surfactant Research at the University of Oklahoma. He is currently a research fellow at the Huntsman Corporation, and manages the Home, Personal Care and Industrial Additives Technology group for the Americas. 